\title{
The Effects of Arbuscular Mycorrhizal Fungi on Direct and Indirect Defense Metabolites of Plantago lanceolata L.
}

\author{
Anna Fontana • Michael Reichelt • Stefan Hempel • \\ Jonathan Gershenzon • Sybille B. Unsicker
}

Received: 20 February 2009 /Revised: 05 June 2009 / Accepted: 11 June 2009/Published online: 2 July 2009

(C) The Author(s) 2009. This article is published with open access at Springerlink.com

\begin{abstract}
Arbuscular mycorrhizal fungi can strongly influence the metabolism of their host plant, but their effect on plant defense mechanisms has not yet been thoroughly investigated. We studied how the principal direct defenses (iridoid glycosides) and indirect defenses (volatile organic compounds) of Plantago lanceolata L. are affected by insect herbivory and mechanical wounding. Volatile compounds were collected and quantified from mycorrhizal and non-mycorrhizal $P$. lanceolata plants that underwent three different treatments: 1) insect herbivory, 2) mechanical wounding, or 3) no damage. The iridoids aucubin and catalpol were extracted and quantified from the same plants. Emission of terpenoid volatiles was significantly higher after insect herbivory than after the other treatments. However, herbivore-damaged mycorrhizal plants emitted lower amounts of sesquiterpenes, but not monoterpenes, than herbivore-damaged non-mycorrhizal plants. In contrast, mycorrhizal infection increased the emission of the green leaf volatile $(Z)$-3-hexenyl acetate in untreated control plants, making it comparable to emission from mechanically wounded or herbivore-damaged plants whether or not they had mycorrhizal associates. Neither mycorrhization nor treatment had any influence on the levels of iridoid glycosides. Thus, mycorrhizal infection did not have any
\end{abstract}

A. Fontana $\cdot$ M. Reichelt $\cdot$ J. Gershenzon $\cdot$ S. B. Unsicker $(\triangle)$ Department of Biochemistry,

Max Planck Institute for Chemical Ecology,

Hans-Knöll Straße 8,

07745 Jena, Germany

e-mail: sunsicker@ice.mpg.de

S. Hempel

Department of Soil Ecology, UFZ - Helmholtzcentre

for Environmental Research,

Theodor-Lieser-Straße 4,

06120 Halle (Saale), Germany effect on the levels of direct defense compounds measured in P. lanceolata. However, the large decline in herbivoreinduced sesquiterpene emission may have important implications for the indirect defense potential of this species.

Keywords Arbuscular mycorrhizal fungi (AMF) - Volatile organic compounds (VOC) · Iridoid glycosides (IG) .

Plantago lanceolata $\cdot$ Spodoptera littoralis · Glomus intraradices Plant secondary metabolites

\section{Introduction}

About $80 \%$ of all terrestrial plants form associations with arbuscular mycorrhizal fungi (AMF) (Wang and Qiu 2006). These are fungal symbionts that are well known to improve plant nutritional status by enhancing the uptake of essential nutrients such as phosphorous and nitrogen and by improving the water supply through an increase in root surface area (Smith and Read 1997). In return, fungi receive carbon in the form of photosynthates from the plant.

For both the establishment and the maintenance of the symbiotic association between plants and AMF, it is essential that both partners recognize each other. These recognition processes are initiated via molecular cross-talk mediated by changes in the gene expression and production of signal compounds in both partners (Harrison 2005). On the plant side, altered gene expression in the presence of AMF can influence other aspects of metabolism and even result in the induction of chemical defenses (Gange et al. 2007). A number of studies in the recent past have reported the effects of AMF on plant defensive compounds, such as volatile terpenoids (Akiyama and Hayashi 2002; Rapparini et al. 2008), essential oils (Copetta et al. 2006; Khaosaad et al. 2006) and glucosinolates (Vierheilig et al. 2000). 
Furthermore, effects of AMF on salicylic acid (SA) and jasmonate dependent signaling pathways have been reported, suggesting that AMF modulate plant defenses (review by Pozo and Azcòn-Aguilar 2007 and references therein). AMF invasion triggers a general plant response to pathogen attack (Dumas-Gaudot et al. 2000), causing a transient accumulation of SA and activation of the SAdependent signaling pathway at the early stages of the association. These responses then seem to be repressed once the compatibility of the symbionts is recognized (reviewed by Garcia-Garrido and Ocampo 2002).

Two major forms of plant anti-herbivore defenses can be distinguished: direct defenses, which are toxic to the herbivore or deter feeding, and indirect defenses, which protect the plant by attracting natural enemies of the herbivore, either parasitoids or predators. Direct and indirect defenses can be constitutively expressed or induced by mechanical damage or herbivore feeding. The literature on mycorrhizal influence on direct and indirect defenses and the consequences for insect herbivores is scarce (Gange et al. 2007; Hartley and Gange 2009), although some studies that show the effects of AMF on direct defenses have been published (e.g., Marak et al. 2002; Fuchs and Bowers 2004). A major group of indirect plant defenses are volatile organic compounds (VOCs) that consist principally of green leaf volatiles (GLVs) and mono- and sesquiterpenes (Pichersky and Gershenzon 2002; Degenhardt et al. 2003). Herbivore-induced VOCs play an important role in attracting natural enemies of insect herbivores (e.g., Dicke et al. 1990; Turlings et al. 1990; Kessler and Baldwin 2001). Furthermore, herbivore-induced VOCs act as both intra- and inter- plant signals, and can result in priming and induction of plant defenses (e.g. Kost and Heil 2006; Frost et al. 2007; Heil and Silva Bueno 2007).

Naturally occurring VOC emissions have been compared in mycorrhizal vs. non-mycorrhizal plants. For example, mycorrhization of Artemisia annua L. with two AMF species did not affect the amount of total terpenes emitted, but there were slight changes in the relative quantities of single compounds (Rapparini et al. 2008). In addition, an unspecialized fungal root endophyte (Acremonium strictum) reduced terpene emission of tomato plants with consequences for insect oviposition preference (Jallow et al. 2008). However, no study to date has investigated how herbivore damage alters the production of defenses in AMF vs. nonAMF plants, even though herbivory is known to have marked effects on VOC emission profiles and the levels of other defense compounds.

Plantago lanceolata $\mathrm{L}$. is a perennial forb with a cosmopolitan distribution and commonly forms associations with a large number of AMF species (Johnson et al. 2004; Oehl et al. 2004). The main group of secondary metabolites in P. lanceolata is the iridoid glycosides, with two dominant compounds, namely aucubin and catalpol. These compounds function as feeding and oviposition stimulants for specialized insects, and as deterrents or toxins for generalist herbivores (e.g., Bowers and Puttick 1988, Biere et al. 2004). Antimicrobial functions of these monoterpene derivatives also have been documented (Marak et al. 2002). The association of $P$. lanceolata with AMF can modify plant defense properties. In a study by Gange and West, the levels of the two iridoid glycosides (IGs), aucubin and catalpol, increased when the plants were associated with AMF (Gange and West 1994). However, the effects of AMF on other groups of defensive compounds in $P$. lanceolata, such as green leaf volatiles or volatile terpenoids, have not yet been documented.

In this study, we investigated the effects of the arbuscular mycorrhizal fungus Glomus intraradices (N.C. Schenck \& G.S. Sm.) on P. lanceolata by focusing on two groups of compounds, IGs and VOCs, that typically act as direct and indirect plant defenses, respectively. In an experiment with a full factorial design, we compared VOC emissions and the IG contents of AMF-inoculated and non-inoculated P. lanceolata individuals after mechanical wounding and caterpillar herbivory with those of nontreated control plants.

Mycorrhizal fungi could influence a plant's allocation to defense in different ways: 1) Altering nutritional status of the host plant: Greater nutrient availability could lead to an increase in primary productivity that provides more resources for the plant to use in the biosynthesis of defensive metabolites, such as IGs or VOCs. On the other hand, harboring AMF is no guarantee of increased productivity, since in return for nutrients, plants provide symbiotic fungi with photosynthates. If the outflow of photosynthates to the fungal symbionts is greater than the increase in productivity due to enhanced nutrient supply, there may be a net decrease in carbon supply that could lead to a decline in defense metabolism. This decline might affect the production of direct vs. indirect defenses differently depending on the relative value of these defensive strategies under different nutritional conditions. 2) Altering signalling pathways: Independent of plant nutritional status, the presence of microorganisms, including AMF, could alter defense signalling. Microbial infection generally is known to activate many types of defense responses, although mycorrhizal fungi usually elicit only attenuated responses (Garcìa-Garrido and Ocampo 2002).

\section{Methods and Materials}

Plant, Fungus and Insect Material Seeds of P. lanceolata (Rieger \& Hofmann, Germany) were sown in trays filled with commercially available sowing soil (Stender 
Vermehrungssubstrat A210, Stender, Germany) that was previously autoclaved for $20 \mathrm{~min}$ at $121^{\circ} \mathrm{C}$, in order to kill potential AMF propagules. P. lanceolata germinated and grew in a greenhouse (day:night temperatures $20-22^{\circ} \mathrm{C}$ : $18-20^{\circ} \mathrm{C}, 30-55 \%$ humidity, $16 \mathrm{~h}$ light, photosynthetically-

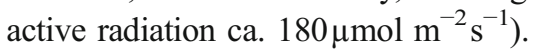

To prepare a growing medium, soil from a meadow in proximity to the greenhouse (in Jena, Germany) was mixed with sand in a $1: 1\left(\mathrm{w} \mathrm{w}^{-1}\right)$ proportion, and autoclaved for $20 \mathrm{~min}$ at $121^{\circ} \mathrm{C}$. Thereafter, 178 pots $(14.4 \mathrm{~cm}$ diam, $1.3 \mathrm{l})$ were each filled with $300 \mathrm{ml}$ of the soil-sand mixture and watered with $10 \mathrm{ml}$ soil suspension $(500 \mathrm{~g}$ fresh soil suspended in 51 tap water, filtered through a $25 \mu \mathrm{m}$ Whatman filter to exclude AMF propagules) in order to allow the establishment of a new microbial community in the sterile soil mixture (Schroeder and Janos 2004). Afterwards, all pots were covered with gauze to prevent the soil from desiccation.

Glomus intraradices inoculum was purchased from Amykor (Germany) (strain AMYKOR1), and half of it was autoclaved for $30 \mathrm{~min}$ at $121^{\circ} \mathrm{C}$. Half of the 178 pots were then inoculated with $5 \mathrm{~g}$ of AMF vital inoculum each ("mycorrhizal plants"), the other half were mock inoculated with the same quantity of AMF autoclaved inoculum ("nonmycorrhizal" plants). The inoculum was mixed with the upper layer $(3-4 \mathrm{~cm})$ of the soil-sand mixture, and the $P$. lanceolata seedlings were transplanted individually into the pots.

Due to a thrips infestation, all plants were treated once with Conserve (Dow AgroSciences LLC, USA) (Conserve $0.075 \%, 0.51$ spray for all the 178 plants) $5 \mathrm{wk}$ after transplantation.

Caterpillars of the generalist feeder Spodoptera littoralis Boisd. (Lepidoptera: Noctuidae) (Syngenta, Basel, Switzerland), were reared on an artificial bean diet at $21^{\circ} \mathrm{C}$. The diet was prepared by mixing 11 tap water with $1 \mathrm{~kg}$ beans, $18 \mathrm{~g}$ ascorbic acid, $10 \mathrm{~g}$ 4-ethylbenzoic acid, $18 \mathrm{~g}$

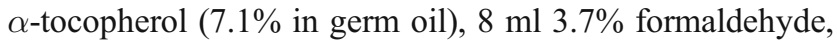
and 2.41 of a $5 \%$ agar solution) at $21^{\circ} \mathrm{C}$. Third-instar caterpillars were starved for $24 \mathrm{~h}$ before they were used in the experiment.

Experimental Setup and Plant Treatments Plants were divided between mycorrhizal and non- mycorrhizal treatments, and 15 plants of a single treatment were placed in one tray $(60 \times 40 \mathrm{~cm})$. The trays were positioned on a greenhouse bench in two rows, one with mycorrhizal plants and the other without, in order to avoid cross infection of AMF. Tray position on the greenhouse bench was shifted weekly to control for any differences in light or temperature conditions.

The experiment started 52 days after seedling transplantation and lasted for $18 \mathrm{~d}$. Treatment of the plants started in the evening, and was performed as follows: six to seven mycorrhizal and the same number of non-mycorrhizal plants were randomly chosen and moved separately to two different trays. Plants in each tray then were divided into three groups that underwent the following treatments: Group 1 - Mechanical wounding (MW): young and old leaves were evenly damaged by punching ten $4 \mathrm{~mm}$ holes per plant with a ticket puncher. The same treatment was repeated on the following day, before the volatile collection started. Group 2 - Herbivory (H): six third-instar S. littoralis caterpillars per plant were allowed to feed overnight on the foliage. Group 3 - Control (C): control plants received no damage. The foliage of both the treated and the control plants was enclosed within a cellophane bag $(205 \times 380 \mathrm{~mm}$, Unipack, Germany) to prevent caterpillars from escaping. In total, 32 mycorrhizal and 32 non-mycorrhizal plants underwent the MW treatment, 29 mycorrhizal and 29 nonmycorrhizal plants underwent the $\mathrm{H}$ treatment, and 28 mycorrhizal and 28 non-mycorrhizal underwent the $\mathrm{C}$ treatment.

The following morning volatile organic compounds were collected from all plants. Cellophane bags and caterpillars were removed before the volatile collection started.

Plant Volatiles Volatile organic compounds emitted by $P$. lanceolata after herbivory, mechanical wounding, or control treatment were collected in a dynamic headspace collection system located in a growth chamber set at $20^{\circ} \mathrm{C}, 55 \%$ relative humidity and $85 \pm 5 \mu \mathrm{mol} \mathrm{m} \mathrm{m}^{-2} \mathrm{~s}^{-1}$ photosynthetically-active radiation.

Approximately $16 \mathrm{~h}$ after the start of the treatments $(\mathrm{H}$, MW, and C), each potted plant was placed individually in a 31 glass desiccator (Schott, Germany). Each desiccator was tightly closed with a glass lid equipped with a valve that allowed air, which was previously purified through a charcoal filter, to enter the enclosure. The incoming air flux was adjusted to $2 \pm 0.31 \mathrm{~min}^{-1}$. After being in contact with the plant, the air exited the glass cylinder through a collection trap (4 mm diam glass tube containing $30 \mathrm{mg}$ Super Q (ARS, Gainesville, FL, USA), positioned in an opening in the lid.

All VOC collections were performed within a six-hour timeframe from around 10 am to $4 \mathrm{pm}$ to minimize variation in volatile emissions due to plant diurnal rhythm. After $4 \frac{1}{2} \mathrm{~h}$ VOC collection, the Super Q traps were eluted with $150 \mu 1$ dichloromethane that contained 1500 ng nonylacetate as an internal standard.

VOCs were identified with a Hewlett-Packard model 6890 gas chromatograph employing the carrier gas $\mathrm{He}$ at $1 \mathrm{ml} \mathrm{min}{ }^{-1}$, splitless injection (injection temperature: $220^{\circ} \mathrm{C}$, injection volume: $\left.1 \mu \mathrm{l}\right)$, a DB-5MS column $(30 \mathrm{~m} \times 0.25 \mathrm{~mm} \times 0.25 \mu \mathrm{m}$ film, J \& W Scientific, Folsom, USA), and a temperature program from $40^{\circ} \mathrm{C}(2 \mathrm{~min}$ hold $)$ to $300^{\circ} \mathrm{C}(2$ min hold $)$ with a first gradient of $7^{\circ} \mathrm{C} \mathrm{min}^{-1}$ to 
$155^{\circ} \mathrm{C}$ and a second gradient of $60^{\circ} \mathrm{C} \min ^{-1}$ to $300^{\circ} \mathrm{C}$. Coupled to the gas chromatograph was a mass spectrometer (Hewlett-Packard model 5973) with a quadrupole mass selective detector; transfer line temperature, $270^{\circ} \mathrm{C}$; ionization potential, $70 \mathrm{eV}$; and a scan range of $\mathrm{m} / \mathrm{z} 40-350$. For quantification, a GC was coupled to a FID detector operating at $250^{\circ} \mathrm{C}$, using the same conditions described above.

VOCs were first identified on the GC-MS by reference spectra in the Wiley and National Institute of Standards and Technology libraries and in the literature (Joulain and König 1998) and by comparison of retention times and mass spectra to those of standards in our collection and others kindly supplied by Wilfried A. König, Hamburg (essential oils of Oreodaphne porosa and Aloysia sellowii). Quantification of the identified compounds was carried out by comparing the peak areas in the FID traces with that of the internal standard, applying a response factor of 1 for the internal standard, 1.11 for (Z)-3-hexenyl acetate, 0.75 for $(E)$ - $\beta$-ocimene and $(E)-4,8$ dimethyl-1,3,7-nonatriene (DMNT), and 0.74 for all the sesquiterpenes (calculated according to the effective carbon number concept (Scanion and Willis 1985)). In addition to the 6 major compounds discussed in the "Results" section, other compounds were identified in a subgroup of the 29 plants subjected to herbivory treatment ( $N=$ number of individuals from which the particular VOC was identified): limonene $(N=11)$, $\alpha$-copaene $(N=12), \beta$-elemene $(N=5), \alpha$-humulene $(N=5)$, $\alpha$-muurolene $(N=2), \delta$-cadinene $(N=2)$. As the sum of these terpenoids never exceeded $7 \%$ of the total volatiles, they were not included in further analyses.

Plant Performance After VOC collection, the aboveground parts of all plants were cut at ground level, and the number of leaves and fresh weight were recorded for each plant. In order to estimate the amount of leaf area lost due to caterpillar feeding in the herbivore treatment, the leaves from these plants were aligned on a white board together with a reference area of $2.25 \mathrm{~cm}^{2}$ and photographed with a digital camera. Digital images were analyzed with Adobe Photoshop (Adobe Systems Incorporated, USA). By referring to the amount of pixels in the reference area, actual remaining leaf areas were determined. Leaf area loss due to caterpillar feeding then was reconstructed by using the remaining leaf area as a template. After photographing, leaves of all plants were frozen in liquid nitrogen and freeze dried. Then, the dry weight of each individual was measured.

Iridoid Glycosides Iridoid glycosides were extracted from $25 \mathrm{mg}$ of freeze dried, finely ground leaf material with $1.8 \mathrm{ml}$ methanol. After $6 \mathrm{~h}$ extraction, leaf material was centrifuged at $16000 \mathrm{~g}$, and the supernatant was transferred into clean tubes and evaporated to dryness under nitrogen. The pellet was redissolved in $500 \mu \mathrm{l}$ of a $20 \%$ methanol solution and centrifuged at $16000 \mathrm{~g}$ (modified from Marak et al. 2002). Separation of iridoid glycosides was achieved on a Hewlett Packard HP 1100 Series HPLC system with autosampler and diode-array detector. The procedure employed a $\mathrm{C}-18$ reversed phase column (Supelcosil LC18, 250×4.6 mm i.d., $5 \mu \mathrm{m}$ particle size, Supelco) operated at $1 \mathrm{ml} \mathrm{min}{ }^{-1}$ and $25^{\circ} \mathrm{C}$. Injection volume was $20 \mu \mathrm{l}$. Elution was accomplished with a gradient (solvent A: 0,05\% trifluoroacetic acid, solvent B: $\mathrm{MeCN}$ ) of $0-15 \% \mathrm{~B}$ (15 min), followed by a cleaning cycle (15-100\% B in $0.5 \mathrm{~min}, 2.5 \mathrm{~min}$ hold, 100 to $0 \% \mathrm{~B}$ in $0.1 \mathrm{~min}, 5 \mathrm{~min}$ hold). Eluting compounds were monitored at $200 \mathrm{~nm}$, and peaks were identified by match of retention time and UV spectrum with those of commercial standards (catalpol, Wako Chemicals; aucubin, Carl Roth, Germany). Additionally, the identity of catalpol and aucubin was confirmed by LC-MS. Concentrations of iridoid glycosides were calculated by using response curves generated with external standards of catalpol and aucubin.

Mycorrhization Rates For the determination of mycorrhization rate, a subset of 30 mycorrhizal and 30 nonmycorrhizal plants was sampled so that an equal number of individuals from each treatment $(\mathrm{H}, \mathrm{MW}$, and $\mathrm{C}$ ) and from each day of volatile collection were included. Immediately after removal of the leaves, roots were rinsed carefully to wash off the soil, fixed in formaldehyde-acetic-acid [FAA: $6.0 \%$ formaldehyde, $2.3 \%$ glacial acetic acid, 45.8\% ethanol and 45.9\% $\left.\mathrm{H}_{2} \mathrm{O}\left(\mathrm{v} \mathrm{v}^{-1}\right)\right]$, and stored at $4{ }^{\circ} \mathrm{C}$. Fixed roots were washed with distilled water, cut in segments of approximately $1.5 \mathrm{~cm}$, and heated at $90^{\circ} \mathrm{C}$ for $10 \mathrm{~min}$ in $10 \% \mathrm{KOH}$. Afterwards, roots were rinsed in tap water, acidified to $3.7 \% \mathrm{HCl}$ for $10 \mathrm{~min}$, and stained for $11 \mathrm{~min}$ in a ready-to-use lactophenol blue solution (Fluka, Switzerland) (Phillips and Hayman 1970). The stain in excess was removed in 50\% lactic acid. Total mycorrhizal colonization rates (percentage of the examined root segments with mycorrhizal structures) were determined microscopically using the line intersect method (Phillips and Hayman 1970), modified after Schmitz et al. (1991). Stained root segments from one single plant were densely packed on a microscope slide. A minimum of 300 visual fields per slide were observed at $200 \times$ magnification .

Plant and Soil Nutrient Analysis Freeze dried, finely ground plant material $(300 \mathrm{mg})$ and the sand-soil mixture in which the plants grew $(500 \mathrm{mg}$ ) were analyzed for total carbon and nitrogen content with an elemental analyzer (Vario MAX CNS, Elementar, Hanau, Germany). 
Statistical Analysis In order to analyze the influence of mycorrhization and treatments $(\mathrm{H}, \mathrm{MW}$, and $\mathrm{C})$ on the amount of 1) the individual volatile compounds, 2) the total amount of terpenes, and 3) the amount of GLVs emitted and corrected for the dry weight of the plants at the same time, analysis of covariance (ANCOVA) was used. Type of treatment and presence of mycorrhiza were considered as fixed factors, and dry weight was fitted in the model as a continuous covariate. Data were either cube root (total terpenes and GLV) or log transformed (single volatiles), and quantities equal to zero were excluded from the analysis of single volatiles to match the prerequisites for ANCOVA. Whenever possible, models were simplified by removing non-significant terms (Crawley 2007). Significance of differences between factor levels were tested by Tukey multiple comparisons of means.

As for volatiles, the influence of mycorrhization and treatments was analyzed on catalpol and aucubin levels. Since IGs are constitutively produced compounds known to accumulate during plant development (Barton 2007), time was fitted to the model as a covariate. Time was indicated as the number of days (1 to 18) from the start of the experiment, i.e., from the day of the treatment of the first set of plants. Catalpol quantities were square-root transformed before analysis to fulfil the requirements for ANCOVA.

Significance of differences in aboveground biomass (dry weight), leaf number, herbivory rates, and carbon and nitrogen content between mycorrhizal and non-mycorrhizal plants was tested by Student's $t$-test.

All statistical analyses were performed with software package R (R Development Core Team (2008), R: A language and environment for statistical computing. R Foundation for Statistical Computing, Vienna, Austria. ISBN 3-900051-07-0, URL http://www.R-project.org.).

\section{Results}

Plant Volatiles Plantago lanceolata plants emitted a volatile bouquet dominated by the green leaf volatile (GLV), (Z)-3-hexenyl acetate, as well as terpenoids of different classes. In order to assess the effect of mycorrhization and different treatments on the volatile emission of $P$. lanceo$l a t a$, we quantified the six major volatile compounds, which together make up between $70-90 \%$ of the total mixture in herbivory treated and mechanically wounded plants. These include the green leaf volatile $(Z)$-3-hexenyl acetate, the monoterpene $(E)$ - $\beta$-ocimene, the $\mathrm{C}_{11}$ homoterpene $(E)-4,8$ dimethyl-1,3,7-nonatriene (DMNT), and the sesquiterpenes $(E)$ - $\beta$-caryophyllene, $(E)$ - $\alpha$-bergamotene, and $(E)$ - $\beta$-farnesene. The volatile organic compound (VOC) emission profile of $P$. lanceolata was significantly different among plants in the different treatments (Fig. 1a, Table 1). Most strikingly, herbivore-damaged plants emitted much higher levels of terpenoids than mechanically-damaged plants or undamaged controls (Fig. 1a, Table 1).

There were significant differences between mycorrhizal and non-mycorrhizal plants. Mycorrhizal plants emitted about $55 \%$ less total terpenoids compared to nonmycorrhizal plants in the herbivory treatment (mycorrhiza: $F_{1,171}=5.11, P=0.039$; interaction mycorrhiza:treatment: $F_{2,171}=8.14, P<0.001$; Fig. 2a). Among the classes of terpenoids, the emission of sesquiterpenes was $63 \%$ lower in mycorrhizal compared to non-mycorrhizal plants after herbivory (Table 1), but the emission of monoterpene, $(E)$ $\beta$-ocimene, was not affected by this treatment $\left(F_{1,83}=0.04\right.$, $P=0.845$, Table 2).
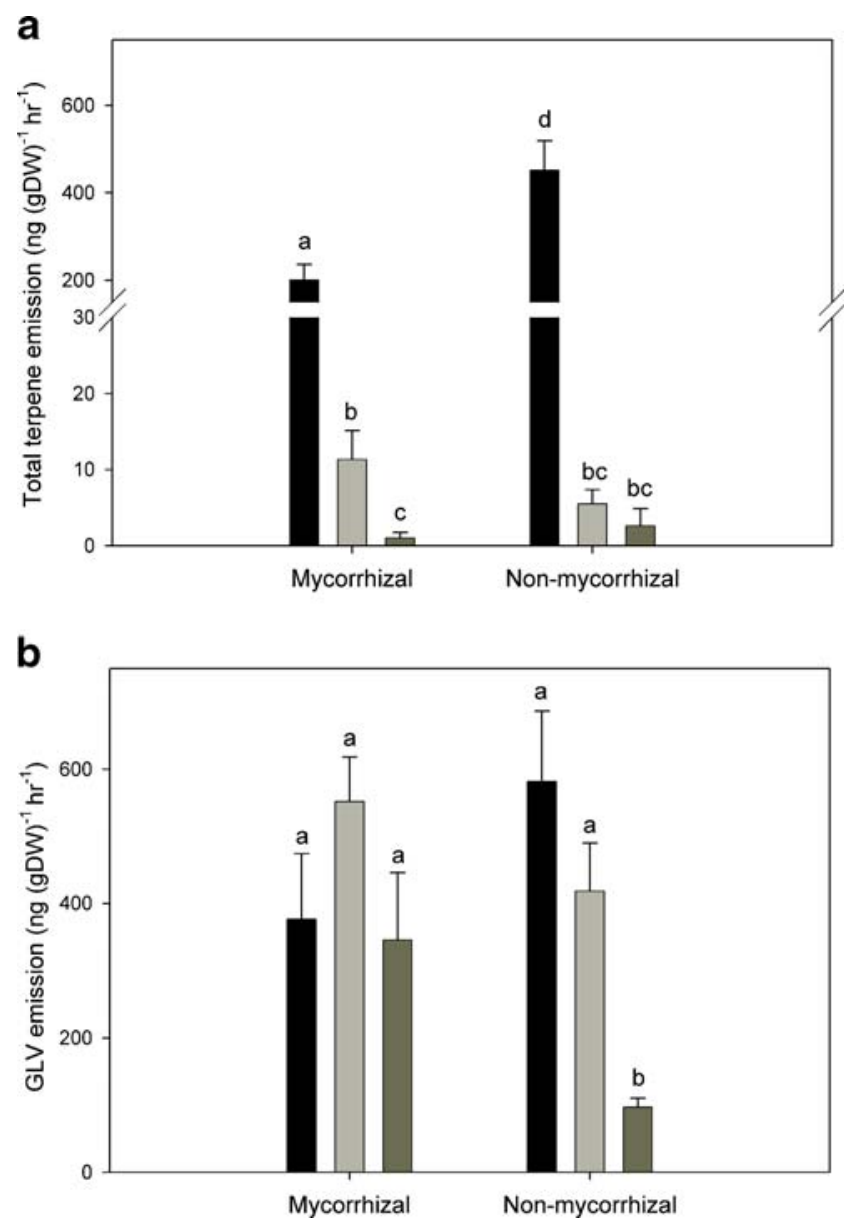

Fig. 1 Total emission of terpenes (a) and green leaf volatiles (GLV) (b) from Plantago lanceolata after herbivory (black bars) and mechanical wounding (light gray bars) in comparison to untreated control plants (dark grey bars). Bars represent means \pm SE. Different letters indicate significant differences between the means according to ANCOVA followed by Tukey test (adjusted $P<0.05$ ) 
Table 1 Emission rate of the six major volatiles and content of the iridoid glycosides in the leaves of herbivory-treated, mechanically wounded and untreated control Plantago lanceolata plants

\begin{tabular}{|c|c|c|c|c|c|c|}
\hline \multirow[t]{2}{*}{ Compound } & \multicolumn{3}{|l|}{ Mycorrhizal } & \multicolumn{3}{|l|}{ Non-mycorrhizal } \\
\hline & Herbivory & Mechanical wounding & Control & Herbivory & Mechanical wounding & Control \\
\hline \multicolumn{7}{|l|}{ Volatiles } \\
\hline \multicolumn{7}{|c|}{$\mathrm{ng}(\mathrm{gDW})^{-1} \mathrm{hr}^{-1} ;$ mean $\pm \mathrm{SE}$} \\
\hline (Z)-3-hexenyl acetate & $376.61 \pm 97.56$ & $552.15 \pm 65.96$ & $364.37 \pm 99.6$ & $581.96 \pm 104.68$ & $376.61 \pm 71.3$ & $97.19 \pm 13.59$ \\
\hline$(E)-\beta$-ocimene & $75.37 \pm 15.19$ & $6.94 \pm 2.21$ & $1.01 \pm 0.71$ & $103.04 \pm 17.41$ & $4.06 \pm 1.10$ & $0.94 \pm 0.60$ \\
\hline DMNT & $22.05 \pm 4.64$ & $0.19 \pm 0.19$ & 0.00 & $68.65 \pm 11.71$ & $0.70 \pm 0.52$ & 0.00 \\
\hline$(E)$ - $\beta$-caryophyllene & $45.90 \pm 10.06$ & $2.23 \pm 0.92$ & 0.00 & $107.69 \pm 25.83$ & $0.23 \pm 0.19$ & $0.65^{\mathrm{a}}$ \\
\hline (E)- $\alpha$-bergamotene & $25.84 \pm 5.03$ & $1.13 \pm 0.81$ & 0.00 & $70.16 \pm 12.64$ & $0.45^{\mathrm{a}}$ & $0.45^{\mathrm{a}}$ \\
\hline$(E)$ - $\beta$-farnesene & $31.84 \pm 8.05$ & $0.88 \pm 0.61$ & 0.00 & $101.75 \pm 21.67$ & 0.00 & $0.59^{\mathrm{a}}$ \\
\hline \multirow{2}{*}{\multicolumn{7}{|c|}{$\begin{array}{l}\text { Iridoid glycosides } \\
\mu \mathrm{g}(\mathrm{mgDW})^{-1} ; \text { mean } \pm \mathrm{SE}\end{array}$}} \\
\hline & & & & & & \\
\hline Catalpol & $2.79 \pm 0.32$ & $2.87 \pm 0.35$ & $3.26 \pm 0.34$ & $3.03 \pm 0.32$ & $2.95 \pm 0.33$ & $2.94 \pm 0.47$ \\
\hline Aucubin & $7.13 \pm 0.58$ & $6.61 \pm 0.54$ & $6.89 \pm 0.49$ & $7.35 \pm 0.51$ & $6.54 \pm 0.60$ & $5.37 \pm 0.54$ \\
\hline
\end{tabular}

${ }^{\mathrm{a}}$ These volatiles were emitted by a single plant, therefore the SE has not been calculated

For (Z)-3-hexenyl acetate, the only major GLV detected, mycorrhizal infection increased emission of undamaged plants more than 3-fold compared to undamaged nonmycorrhizal plants. Herbivory and mechanical wounding of mycorrhizal plants caused no further increase in the emission of this GLV, while these treatments did increase emission from non-mycorrhizal plants by over 5-fold (Fig. 1b).

The ANCOVA showed no significant interactions between the quantity of any of the terpenes and plant dry weight. However, a significant interaction of dry weight and mycorrhization $\left(F_{4,170}=4.36, P=0.038\right.$, Table 2$)$ was found for $(Z)-3$-hexenyl acetate. This means that the effect of mycorrhization on GLV emission varied according to plant biomass. In small plants, mycorrhization increased (Z)-3-hexenyl acetate emission, while it had the opposite effect on larger plants (Fig. 2).

Plant Performance The total aboveground biomass of mycorrhizal plants was on average $8.5 \%$ lower than nonmycorrhizal plants (fresh weight: $t_{1,175}=-3.19, P=0.002$, dry weight: $t_{1,176}=3.87, P<0.001$ ) (Fig 3). This result might be attributed to a drain of fixed carbon toward the fungus in mycorrhizal plants. In fact, mycorrhizal plants contained less carbon in their leaves compared to nonmycorrhizal plants (average $\mathrm{C} \%$ : mycorrhizal plants= $41.4 \%$, non-mycorrhizal plants $=42.3 \%$; Student's $t$-test, $\left.t_{1,24}=-3.98, P<0.001\right)$, but nitrogen content did not vary between leaves of mycorrhizal and non-mycorrhizal plants ( $\mathrm{N} \%=0.81 \%$ in both groups). The $\mathrm{C} / \mathrm{N}$ ratio of the sand-soil mixture where the plants were grown was $23.15 \pm 0.35$ (mean \pm SE, $N=4)$. Non-mycorrhizal plants had on average a higher number of leaves compared to the mycorrhizal plants (mean non-mycorrhizal: 12.10, mean mycorrhizal: 11.40, $\left.t_{1,162}=-1.87, P=0.063\right)$.

Mycorrhization did not influence the feeding behaviour of S. littoralis caterpillars. The amount of leaf tissue consumed overnight was the same in mycorrhizal and non-mycorrhizal plants. $\left(t_{1,53}=-0.83, P=0.411\right)$.

Iridoid Glycosides The two main iridoid glycosides (IGs) catalpol and aucubin did not show any significant change in

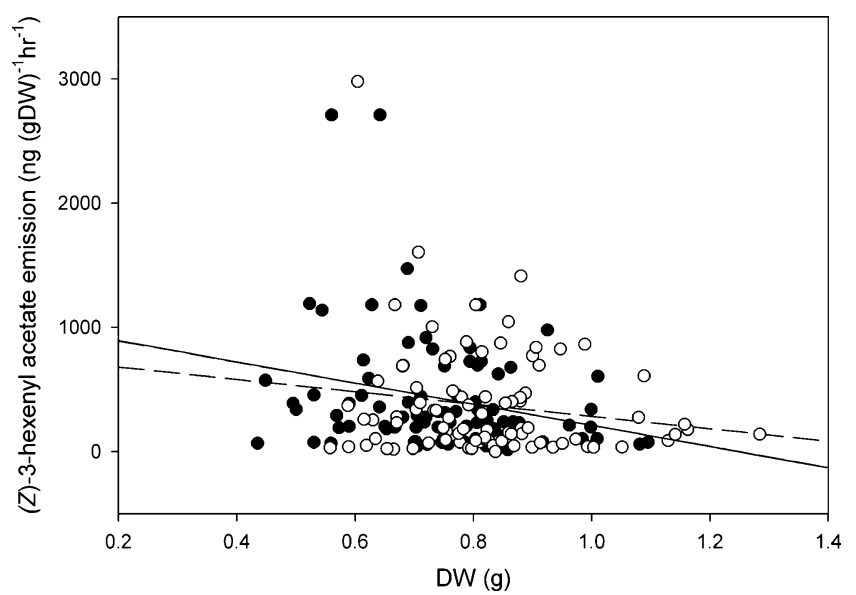

Fig. 2 Linear regression of (Z)-3-hexenyl acetate emission and plant dry weight for mycorrhizal (solid line) and non-mycorrhizal (dashed line) plants. Black dots represent all mycorrhizal plants (herbivorytreated, mechanically wounded and untreated), while open dots represent all non-mycorrhizal plants (herbivory-treated, mechanically wounded and untreated) 
Table 2 ANCOVA summary table for the effects of mycorrhization, treatment and dry weight on the VOC emission of Plantago lanceolata

\begin{tabular}{|c|c|c|c|c|c|c|c|}
\hline \multirow[t]{3}{*}{ VOC } & \multicolumn{4}{|l|}{ Factors } & \multirow{2}{*}{\multicolumn{2}{|c|}{$\frac{\text { Covariate }}{\text { Dry weight }(\mathrm{df}=1)}$}} & \multirow[t]{3}{*}{ df residuals } \\
\hline & \multicolumn{2}{|c|}{ Mycorrhiza $(\mathrm{df}=1)$} & \multicolumn{2}{|c|}{ Treatment $(\mathrm{df}=2)$} & & & \\
\hline & $F$ & $P^{a}$ & $F$ & $P$ & $F$ & $P$ & \\
\hline (Z)-3-hexenyl acetate & 2.45 & $0.119^{\mathrm{b}}$ & 15.47 & $<0.001^{\mathrm{b}}$ & 1.34 & $0.242^{\mathrm{b}}$ & 170 \\
\hline$(E)$ - $\beta$-ocimene & 0.04 & 0.845 & 46.85 & $<0.001$ & 6.78 & 0.011 & 82 \\
\hline DMNT & 7.68 & 0.008 & 8.55 & 0.005 & 1.20 & 0.279 & 48 \\
\hline$(E)-\beta$-caryophyllene & 11.20 & 0.001 & 12.98 & $<0.001$ & 3.00 & 0.089 & 50 \\
\hline (E)- $\alpha$-bergamotene & 18.14 & $<0.001$ & 1.74 & 0.185 & 1.84 & 0.180 & 54 \\
\hline$(E)-\beta$-farnesene & 7.57 & 0.008 & 1.066 & 0.353 & 1.19 & 0.281 & 46 \\
\hline
\end{tabular}

${ }^{a}$ Bold numbers indicate significant effects

${ }^{\mathrm{b}}$ For $(Z)$-3-hexenyl acetate two interactions were significant: mycorrhiza x treatment $(F=8.41, P<0.001)$ and mycorrhiza $\mathrm{x}$ dry weight $(F=4.36$, $P=0.038)$. There was no significant interaction for any of the other volatile organic compounds

quantity, either between the treatments or between mycorrhizal and non-mycorrhizal plants (catalpol: treatment: $F_{2,173}=0.065, P=0.937$, mycorrhiza: $F_{1,173}=0.021, P=$ 0.884 ; aucubin: treatment: $F_{2,173}=2.09, P=0.127$, mycorrhiza: $F_{1,173}=0.98, P=0.322$ ) (Table 1). The cofactor 'time' was significant for both catalpol $\left(F_{1,173}=11.91, P<0.001\right)$ and aucubin $\left(F_{1,173}=8.14, P=0.005\right)$, indicating that the concentration of IGs in the leaves slightly increased over time.

Mycorrhization Rates At the moment of harvest, all inoculated plants were infected by AMF. On average, we found $68 \%$ of the root system colonized by the fungus. No mycorrhizal structures were detected in roots of nonmycorrhizal plants.

\section{Discussion}

Mycorrhizal symbiosis is known to affect many plant parameters, including chemical defense (Gange et al. 2007; Hartley and Gange 2009). To understand fully the effects of this symbiosis on chemical defense, it is necessary to investigate compounds involved in both direct and indirect defense. Indirect defense is often manifested by the herbivore-induced release of volatile organic compounds (VOCs) that attract herbivore enemies. The results from our study show that $P$. lanceolata produces a large increase in volatile terpenoids after herbivory that may serve in indirect defense. However, the association of $P$. lanceolata with the arbuscular mycorrhizal fungus (AMF) $G$. intraradices significantly modifies the release of herbivore-induced VOCs from the plant by reducing the emission of the three major sesquiterpenes and the $C_{11}$ homoterpene, DMNT. As DMNT and sesquiterpenes are prominent components of volatile blends known to act in indirect defense (Turlings et al. 1990), AMF may decrease the ability of herbivore-damaged plants to attract herbivore enemies. Consistent with these results, Jallow and coworkers (2008) recently reported that the inoculation of tomato plant roots with the endophytic fungus Acremonium strictum lead to a reduction in total terpenoid emission. In Artemisia annua, Rapparini et al. (2008) reported that infection with different Glomus species constitutively reduced the amounts of sesquiterpenes produced by undamaged plants compared to non-infected control plants. In contrast, infection had no effect on the amount of monoterpenes emitted by $A$. annua. These findings are consistent with our results from caterpillar-infested $P$. lanceolata plants where the major emitted monoterpene $((E)$ - $\beta$-ocimene) did not differ in its relative release rate between mycorrhizal and non-mycorrhizal plants.

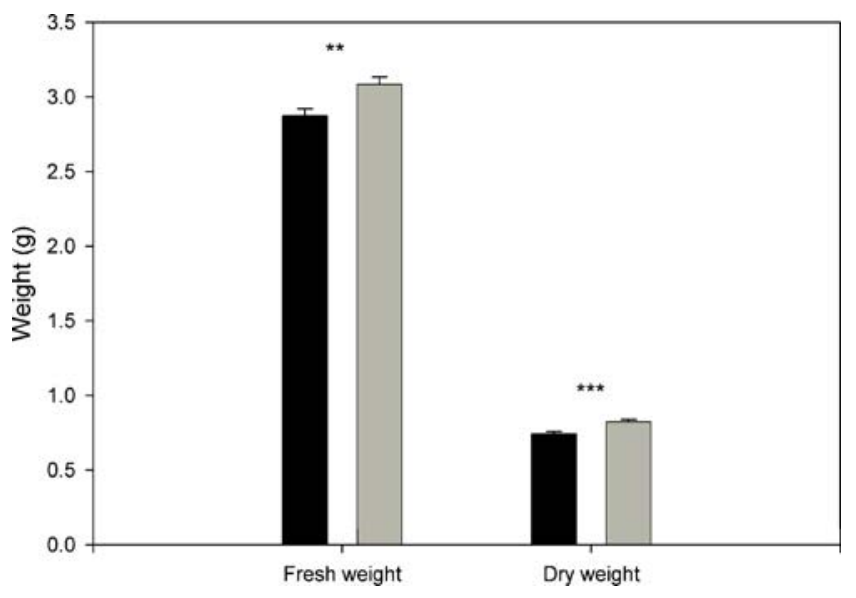

Fig. 3 Aboveground biomass of Plantago lanceolata. Fresh weight was recorded once for each plant, on the day the volatile collection was performed. Black bars $=$ mycorrhizal plants, grey bars $=$ nonmycorrhizal plants. Bars represent means \pm SE. Asterisks represent significant differences according to Student's $t$-test $(* * P<0.01$, $* * * P<0.001$ ) 
Although there is as yet no evidence in the literature that AMF can alter plant indirect defenses, there are reports of the effects of mycorrhization on the major direct defense compounds of $P$. lanceolata, the constitutively produced iridoid glycosides (IGs), aucubin and catalpol. In our study, the levels of IGs were unaffected by mycorrhization. In contrast, a positive effect of mycorrhization on the IG content of $P$. lanceolata was reported by Gange and West (1994), who recorded higher levels of IGs in mycorrhizal compared to non-mycorrhizal plants. The authors attributed this result to the relatively higher fixed carbon levels in the shoots of mycorrhizal plants compared to non-mycorrhizal plants, which allowed more substrate to be allocated to IG production. In contrast, no effect of mycorrhization by $G$. intraradices was found on the catalpol content of $P$. lanceolata leaves by Wurst et al. (2004). Moreover, these authors observed a decrease in leaf carbon content after mycorrhization. We also observed a decrease in leaf carbon levels in the present study, and saw no increase in IG content. This finding supports the hypothesis that IGs are produced in higher amounts after mycorrhization only when symbiosis leads to greater amounts of fixed carbon in the leaves.

Not only did we find a reduction of total leaf carbon content in mycorrhizal plants, but also the aboveground biomass of mycorrhizal plants was lower than that of nonmycorrhizal plants. Although positive effects of AMF on their symbionts' productivity seem to be commonplace (Johnson et al. 1997), neutral or negative effects of mycorrhization on plant growth parameters and biomass also have been documented for P. lanceolata (Ayer et al. 1992; Klironomos 2003; Reynolds et al. 2005) and a number of other plant species (see Johnson et al. 1997 and references therein). That AMF can function as carbon sinks in plants has already been documented (Wurst et al. 2004; Reynolds et al. 2005; Ayres et al. 2006). If the growth of the fungus limits the carbon available to the plant for its basic metabolic requirements, the association could turn from symbiosis into parasitism, a phenomenon that has been attributed by some authors to nutrient-rich substrates, low temperatures, or limiting light conditions (reviewed by Smith and Smith 1996, Purin and Rillig 2008) or to particularly high mycorrhization rates (Gange et al. 1999 and references therein). In addition, AMF can be detrimental in association with particular hosts (Klironomos 2003), and the predisposition of a given fungal strain to parasitism rather than symbiosis seems to be at least partially under genetic control (Johnson et al. 1997). When confronted with a non-beneficial AMF association, plants might reallocate their resources among growth, defense, reproduction, and other functions. In this study of young P. lanceolata, there was a decline in growth, and a reduction in indirect defenses (volatile terpenes), but no change in the level of direct defenses (iridoid glycosides). These findings support our hypothesis that a net decrease in carbon availability caused by the fungus can cause a reduction in allocation to defense (in this case indirect defense). Maintaining high levels of direct chemical defenses in early developmental stages is a strategy adopted by a number of plant species, for example Arabidopsis thaliana (L.) Heynh. (Brown et al. 2003) and Nicotiana sylvestris Spegazzini and Comes (Ohnmeiss and Baldwin 2000). The reduction in indirect defenses observed can also be interpreted as a consequence of the general repression of defenses due to AMF colonization. In the first stages of the association, AMF seem to be able to modulate the defense signaling cascades in the plant, and lower the production of defense compounds (reviewed by GarciaGarrido and Ocampo 2002).

The mechanisms that underlie the induction of volatile terpene emission in $P$. lanceolata after biotic stresses such as herbivore feeding have not yet been elucidated. Terpene biosynthesis is carried out by condensation of $\mathrm{C}_{5}$ isoprenoid units, which, in plants, can derive from two pathways: the methylerythritol phosphate (MEP) pathway, considered the principal route to monoterpene production, and the mevalonate (MVA) pathway, thought to be responsible for the production of sesqui- and triterpenes. The MEP pathway also leads to the production of carotenoids and eventually apocarotenoids, some of which are responsible for the yellow-colored roots seen in a number of species after mycorrhization (Strack et al. 2003). Interest in the function of this yellow pigment has stimulated study of the MEP pathway during mycorrhizal formation. Mycorrhization enhances the transcription of genes encoding 1-deoxy-Dxylulose 5-phosphate synthase (DXS), the enzyme that catalyzes the initial step of the MEP pathway in several species including Medicago truncatula L., Nicotiana tabacum L., Zea mays L., Lycopersicon esculentum Mill., and Triticum aestivum L. (Walter et al. 2000, 2002). An accumulation of transcripts for 1-deoxy-D-xylulose 5phosphate reductoisomerase (DXR), the enzyme immediately downstream from DXS in the MEP pathway, also has been reported in wheat roots after $G$. intraradices infection (Walter et al. 2000). This AMF-mediated activation of the MEP pathway has not yet been examined with respect to the formation of monoterpenes, assumed to be MEP pathway-derived. After mycorrhizal infection of $P$. lanceolata, we observed no change in volatile monoterpene emission or the accumulation of the IGs, which derive from the same biosynthetic route as monoterpenes. Instead, a decrease in sesquiterpenes and DMNT, assumed to be derived from the MVA pathway, was detected. There are no reports in the literature on how the mevalonate pathway is altered by AMF infection.

The production of IGs is known to be strongly dependent on plant age in P. lanceolata (Fuchs and Bowers 
2004; Barton 2007). In the study by Gange and West (1994), who found higher levels of IGs in mycorrhizal compared to non-mycorrhizal plants, IGs were extracted from four-month-old plants, which had been associated with AMF for 14 weeks. In contrast, the plants in the study by Wurst et al. (2004), where the IG content did not change with mycorrhization, and in our study were harvested between 9 and 12 weeks of age with a mycorrhizal period of 7 or 10 weeks, respectively. According to Fuchs and Bowers (2004), the concentration of IGs in P. lanceolata starts increasing 9 weeks after germination, while Barton (2007) found a strong increase in constitutive levels of IGs already after 6.5 weeks, and furthermore detected a positive correlation between growth rate and daily IG production. Direct comparisons of our results with the literature are difficult because of differences in growing conditions and the genetic properties of the plant material. Nevertheless, it seems plausible that the lack of increase in IGs on mycorrhization observed in our plants is due to harvest at a relatively early developmental stage.

The production of the GLV (Z)-3-hexenyl acetate in undamaged mycorrhizal-infected plants was comparable to that in herbivore or mechanically damaged individuals whether or not they were infected with mycorrhizae (Fig 2). Like many volatile terpenes, GLVs have been indicated in attracting insect parasitoids (Hoballah and Turlings 2005; Shiojiri et al. 2006), and can, therefore, be considered indirect defense signals. By increasing the emission of levels of GLVs in undamaged plants, mycorrhizal infection turns these typically induced volatiles into constitutive ones. This constitutively high GLV emission could be a possible explanation for the enhanced attractiveness of mycorrhizal vs. non-mycorrhizal plants to herbivore parasitoids observed by Guerrieri et al. (2004).

Considering the broad distribution and the importance of AMF associations in terrestrial ecosystems in general (Treseder and Cross 2006; van der Heijden et al. 2008) and more specifically in agricultural systems (Sawers et al. 2008), there is a need for further studies to analyze the impacts of mycorrhizal associations on plant defense in a broad range of species and the regulatory mechanisms responsible for these changes. Based on the present results, such investigations should also include an assessment of the mycorrhizal effects on the attraction of herbivore enemies. Since this attraction can vary when a combination of fungal species are associated with one plant (Gange et al. 2003), the effect of simultaneous association of different AMF on plant chemical defenses should also be investigated.

Acknowledgments We thank Carsten Renker, Udo Kornmesser, Andreas Weber and the gardeners of the MPICÖ, Daniel Rosenberger,
Amelie Zander, Tobias Köllner, Grit Kunert, and Tim Walter for their assistance in various aspects of this work. Furthermore, we thank the two anonymous reviewers for the comments on the manuscript. The study was supported by the Max Planck Society.

Open Access This article is distributed under the terms of the Creative Commons Attribution Noncommercial License which permits any noncommercial use, distribution, and reproduction in any medium, provided the original author(s) and source are credited.

\section{References}

AKIYAMA, K., and HAYASHI, H. 2002. Arbuscular mycorrhizal funguspromoted accumulation of two new triterpenoids in cucumber roots. Biosci. Biotechnol. Biochem. 66:762-769.

Ayer, W. A., Craw, P. A., MA, Y.-T., and MiaO, S. 1992. Synthesis of camalexin and related phytoalexins. Tetrahedron 48:2919-2924.

Ayres, R. L., Gange, A. C., and Aplin, D. M. 2006. Interactions between arbuscular mycorrhizal fungi and intraspecific competition affect size, and size inequality, of Plantago lanceolata L. $J$. Ecol. 94:285-294.

BARTON, K. E. 2007. Early ontogenetic patterns in chemical defense in Plantago (Plantaginaceae): Genetic variation and trade-offs. Am. J. Bot. 94:56-66.

Biere, A., MaraK, H. B., and Van Damme, J. M. M. 2004. Plant chemical defense against herbivores and pathogens: generalized defense or trade-offs? Oecologia 140:430-441.

Bowers, M. D., and PutTick, G. M. 1988. Response of generalist and specialist insects to qualitative allelochemical variation. $J$. Chem. Ecol. 14:319-334.

Brown, P. D., Tokuhisa, J. G., Reichelt, M., and Gershenzon, J. 2003. Variation of glucosinolate accumulation among different organs and developmental stages of Arabidopsis thaliana. Phytochemistry 62:471-481.

Copetta, A., Lingua, G., Berta, G., Bardi, L., and Masoero, G. 2006. Three arbuscular mycorrhizal fungi differently affect growth, distribution of glandular trichomes and essential oil composition in Ocimum basilicum var. Genovese. Proceedings of the 1st International Symposium on the Labiatae: Advances in Production, Biotechnology and Utilisation 723:151-156.

Crawley, M. J. 2007. The R Book. Wiley, Chichester.

Degenhardt, J., Gershenzon, J., Baldwin, I. T., and Kessler, A. 2003. Attracting friends to feast on foes: engineering terpene emission to make crop plants more attractive to herbivore enemies. Curr. Opin. Biotechnol. 14:169-176.

Dicke, M., Vanbeek, T. A., Posthumus, M. A., Bendom, N., VAnBoKhoven, H., and Degroot, A. E. 1990. Isolation and identification of volatile kairomone that affects acarine predatorprey interactions - involvement of host plant in its production. $J$. Chem. Ecol. 16:381-396.

Dumas-Gaudot, E., Gollotte, A., Cordier, C., Gianinazzi, S., and Gianinazzi-PeArson, V. 2000. Modulation of host defence systems, pp. 173-200, in Y. Kapulnik and D. D. J. Douds (eds.). Arbuscular Mycorrhizas: Physiology and Function. Kluwer Academic Publishers, Dordrecht, The Netherlands.

Frost, C. J., Appel, M., Carlson, J. E., De Moraes, C. M., Mescher, M. C., and Schultz, J. C. 2007. Within-plant signalling via volatiles overcomes vascular constraints on systemic signalling and primes responses against herbivores. Ecol. Lett. 10:490-498.

Fuchs, A., and Bowers, M. D. 2004. Patterns of iridoid glycoside production and induction in Plantago lanceolata and the importance of plant age. J. Chem. Ecol. 30:1723-1741. 
Gange, A. C., and West, H. M. 1994. Interactions between arbuscular mycorrhizal fungi and foliar-feeding insects in Plantago lanceolata L. New Phytol. 128:79-87.

Gange, A. C., Bower, E., and Brown, V. K. 1999. Positive effects of an arbuscular mycorrhizal fungus on aphid life history traits. Oecologia 120:123-131.

Gange, A. C., Brown V.K., and Aplin, M. A. 2003. Multitrophic links between arbuscular mycorrhizal fungi and insect parasitoids. Ecol. Lett. 6:1051-1055.

Gange, A. C., Ohgushi, T., Craig, T. P., and Price, P. W. 2007. Insect-mycorrhizal interactions: patterns, processes, and consequences, pp. 124-144, in Ecological Communities: Plant Mediation in Indirect Interaction Webs. Cambridge University Press, Cambridge.

GARCIA-GARRIDO, J. M., and OCAMPO, J. A. 2002. Regulation of the plant defence response in arbuscular mycorrhizal symbiosis. $J$. Exp. Bot. 53:1377-1386.

Guerrieri, E., Lingua, G., Digilio, M. C., Massa, N., and Berta, G. 2004. Do interactions between plant roots and the rhizosphere affect parasitoid behaviour? Ecol. Entomol. 29:753-756.

HARRISON, M. J. 2005. Signaling in the arbuscular mycorrhizal symbiosis. Annu. Rev. Microbiol. 59:19-42.

HARTLEY, S. E. and GANGE, A. C. 2009. Impacts of plant symbiotic fungi on insect herbivores: Mutualism in a multitrophic context. Annu. Rev. Entomol. 54:323-342.

HeIL, M., and SiLVA BuENO, J. C. 2007. Within-plant signaling by volatiles leads to induction and priming of an indirect plant defense in nature. PNAS USA 104:5467-5472.

Hoballah, M. E., and Turlings, T. C. J. 2005. The role of fresh versus old leaf damage in the attraction of parasitic wasps to herbivore-induced maize volatiles. J. Chem. Ecol. 31:2003-2018.

Jallow, M. F. A., Dugassa-Gobena, D., and Vidal, S. 2008. Influence of an endophytic fungus on host plant selection by a polyphagous moth via volatile spectrum changes. ArthropodPlant Interact. 2:53-62.

JohnSON, N. C., Graham, J. H., and Smith, F. A. 1997. Functioning of mycorrhizal associations along the mutualism-parasitism continuum. New Phytol. 135:575-586.

JOHNSON, D., VANDENKOORNhUYSE, P. J., LEAKE, J. R., GILBERT, L., Booth, R. E., Grime, J. P., YounG, J. P. W., and Read, D. J. 2004. Plant communities affect arbuscular mycorrhizal fungal diversity and community composition in grassland microcosms. New Phytol. 161:503-515.

Joulain, D., and KöNIG, W. A. 1998. The Atlas of Spectral Data of Sesquiterpene Hydrocarbons. EB-Verlag, Hamburg.

Kessler, A., and BALDWIN, I. T. 2001. Defensive function of herbivore-induced plant volatile emissions in nature. Science 291:2141-2144.

KhaosaAd, T., Vierheilig, H., Nell, M., ZitTerl-Eglseer, K., and NOVAK, J. 2006. Arbuscular mycorrhiza alter the concentration of essential oils in oregano (Origanum sp., Lamiaceae). Mycorrhiza 16:443-446.

KLIRONOMOS, J. N. 2003. Variation in plant response to native and exotic arbuscular mycorrhizal fungi. Ecology 84:2292-2301.

Kost, C., and HEIL, M. 2006. Herbivore-induced plant volatiles induce an indirect defence in neighbouring plants. J. Ecol. 94:619-628.

MARAK, H. B., BIERE, A., and VAN DAMME, J. M. M. 2002. Systemic, genotype-specific induction of two herbivore-deterrent iridoid glycosides in Plantago lanceolata L. in response to fungal infection by Diaporthe adunca (Rob.) Niessel. J. Chem. Ecol. 28:2429-2448.

Oehl, F., Sieverding, E., Mader, P., Dubois, D., Ineichen, K., BOLler, T., and WIEMKEN, A. 2004. Impact of long-term conventional and organic farming on the diversity of arbuscular mycorrhizal fungi. Oecologia 138:574-583.
OHNMEISS T. E., and BALDWIN I. T. 2000. Optimal defense theory predicts the ontogeny of an induced nicotine defense. Ecology 81:1765-1783.

PhILliPS, J. M., and HAYMAN, D. S. 1970. Improved procedures for clearing roots and staining parasitic and vesicular-arbuscular mycorrhizal fungi for rapid assessment of infection. Trans. Br. Mycol. Soc. 55:158-161.

Pichersky, E., and Gershenzon, J. 2002. The formation and function of plant volatiles: perfumes for pollinator attraction and defense. Curr. Opin. Plant. Biol. 5:237-243.

Pozo, M. J., and AzCÓN-AguILAR, C. 2007. Unraveling mycorrhizainduced resistance. Curr. Opin. Plant. Biol. Special Issue on Biotic Interactions - J. Glazebrook and J. Ton (eds). 10:393-398.

PURIN, S., and RILLIG, M. C. 2008. Parasitism of arbuscular mycorrhizal fungi: reviewing the evidence. FEMS Microbiol. Lett. 279:8-14.

RAPPARINI, F., LluSiA, J., and PENUELAS, J. 2008. Effect of arbuscular mycorrhizal (AM) colonization on terpene emission and content of Artemisia annua L. Plant Biol. 10:108-122.

Reynolds, H. L., Hartley, A. E., Vogelsang, K. M., Bever, J. D., and Schultz, P. A. 2005. Arbuscular mycorrhizal fungi do not enhance nitrogen acquisition and growth of old-field perennials under low nitrogen supply in glasshouse culture. New Phytol. 167:869-880.

Sawers, R. J. H., GutJahr, C., and PaszKowski, U. 2008. Cereal mycorrhiza: an ancient symbiosis in modern agriculture. Trends Plant Sci. 13:93-97.

SCANiON, J. T., and Willis, D. E. 1985. Calculation of flame ionization detector relative response factors using the effective carbon number concept. J. Chromat. Sci. 23:333-340.

Schmitz, O., Danneberg, G., Hundeshagen, B., Klingner, A., and BотHE, H. 1991. Quantification of vesicular-arbuscular mycorrhiza by biochemical parameters. J. Plant Physiol. 139:106-114.

Schroeder, M. S., and Janos, D. P. 2004. Phosphorus and intraspecific density alter plant responses to arbuscular mycorrhizas. Plant Soil 264:335-348.

Shiojiri, K., Kishimoto, K., OzaWA, R., KugimiYa, S., Urashimo, S., Arimura, G., Horiuchi, J., NishiokA, T., Matsui, K., and TAKABAYASHI, J. 2006. Changing green leaf volatile biosynthesis in plants: An approach for improving plant resistance against both herbivores and pathogens. PNAS USA 103:16672-16676.

SMith, S. E., and READ, D. J. 1997. Mycorrhizal Symbiosis. Academic Press, London.

SMITH, F. A., and Smith, S. E. 1996. Mutualism and parasitism: Diversity in function and structure in the "arbuscular" (VA) mycorrhizal symbiosis. Adv. Bot. Res. 22:1-43.

Strack, D., Fester, T., Hause, B., Schliemann, W., and Walter, M. H. 2003. Arbuscular mycorrhiza: Biological, chemical, and molecular aspects. J. Chem. Ecol. 29:1955-1979.

Treseder, K. K., and Cross, A. 2006. Global distributions of arbuscular mycorrhizal fungi. Ecosystems 9:305-316.

Turlings, T. C. J., Tumlinson, J. H., and Lewis, W. J. 1990. Exploitation of herbivore-induced plant odors by host-seeking parasitic wasps. Science 250:1251-1253.

VAn Der heijden, M. G. A., Bardgett, R. D., and Van StraAlen, N. M. 2008. The unseen majority: soil microbes as drivers of plant diversity and productivity in terrestrial ecosystems. Ecol. Lett. 11:296-310.

Vierheilig, H., Gagnon, H., Strack, D., and Maier, W. 2000. Accumulation of cyclohexenone derivatives in barley, wheat and maize roots in response to inoculation with different arbuscular mycorrhizal fungi. Mycorrhiza 9:291-293.

Walter, M. H., Fester, T., and Strack, D. 2000. Arbuscular mycorrhizal fungi induce the non-mevalonate methylerythritol phosphate pathway of isoprenoid biosynthesis correlated with 
accumulation of the 'yellow pigment' and other apocarotenoids. Plant J. 21:571-578.

Walter, M. H., Hans, J., and Strack, D. 2002. Two distantly related genes encoding 1-deoxy-D-xylulose 5-phosphate synthases: differential regulation in shoots and apocarotenoidaccumulating mycorrhizal roots. Plant J. 31:243-254.
WANG, B., and QIU, Y. L. 2006. Phylogenetic distribution and evolution of mycorrhizas in land plants. Mycorrhiza 16:299-363.

Wurst, S., Dugassa-Gobena, D., LANGEL, R., BONKOWSKI, M., and SCHEU, S. 2004. Combined effects of earthworms and vesiculararbuscular mycorrhizas on plant and aphid performance. New Phytol. 163:169-176. 